\title{
Biosynthesis of Carbon Spheres for Supercapacitor Electrode Application
}

\author{
Shicheng Wang ${ }^{*}$, Ling Ji and Xiaowen Tang \\ Beijing University of Technology, Beijing, 100124, P.R. China \\ *E-mail: shichengwangtech@foxmail.com
}

doi: $10.20964 / 2017.12 .74$

Received: 18 August 2017 / Accepted: 30 September 2017 / Published: 12 November 2017

\begin{abstract}
In this work, corn starch was used for the synthesis of carbon spheres with a regular and perfect shape based on oxidation and carbonization. Carbon spheres typically exhibit large pore volume, high specific surface area, and a synergistic effect derived from mesopores and micropores. After preparation at $2600{ }^{\circ} \mathrm{C}$, the as-prepared carbon spheres showed a low internal resistance $(0.24 \Omega)$ in $\mathrm{KOH}$ aqueous solution $(6 \mathrm{M})$ and a specific capacitance of $311 \mathrm{~F} / \mathrm{g}$ at a current density of $0.5 \mathrm{~A} / \mathrm{g}$. Even when the current density was as high as $10 \mathrm{~A} / \mathrm{g}$, the electrochemical capacitance was maintained at $196 \mathrm{~F} / \mathrm{g}$.
\end{abstract}

Keywords: Carbon spheres; Supercapacitor; Corn starch; Electrochemical performance; High temperature oxidation

\section{FULL TEXT}

(C) 2017 The Authors. Published by ESG (www.electrochemsci.org). This article is an open access article distributed under the terms and conditions of the Creative Commons Attribution license (http://creativecommons.org/licenses/by/4.0/). 